Jenifer C. Smith, MD

Gil M. Vicente, MD

Department of Otorhinolaryngology Head and Neck Surgery

Jose R. Reyes Memorial Medical Center
Correspondence: Dr. Gil M. Vicente Department of Otorhinolaryngology Head and Neck Surgery

Jose R. Reyes Memorial Medical Center

San Lazaro Compound, Rizal Avenue

Sta. Cruz, Manila 1003

Philippines

Phone: (632) 7119491 local 320

Email: gmvicentemd@yahoo.com

The authors declared that this represents original material that is not being considered for publication or has not been published or accepted for publication elsewhere in full or in part, in print or electronic media; that the manuscript has been read and approved by the authors, that the requirements for authorship have been met by the authors, and that the authors believe that the manuscript represents honest work.

Disclosures: The authors signed disclosures that there are no financial or other (including personal) relationships, intellectual passion, political or religious beliefs, and institutional affiliations that might lead to a conflict of interest.

Presented at the Philippine Society of Otolaryngology Head and Neck Surgery Surgical Innovation and Instrumentation Poster Contest, December 2, 2014. Sofitel Philippine Plaza Hotel, Manila.

\section{(c) (i) $(9)$}

\title{
True Congenital Macroglossia Surgically Managed Using a Modified Kole Technique
}

\section{ABSTRACT}

Objective: To describe a 2-year-old boy with true congenital macroglossia surgically managed using a modified Kole technique.

\section{Methods:}

\author{
Design: Surgical Innovation \\ Setting: Tertiary Government Hospital \\ Patient: One
}

Results: A 2-year-old boy presented with congenital macroglossia, associated with difficulty feeding and phonating. On physical examination, the massive tongue had both increased length and width. At rest, it protruded between the upper and lower teeth with drying and fissuring of the tip. Dribbling of saliva and mandible prognathism were also noted. The child was surgically treated with a modified Kole technique, wherein the apex of the anterior wedge resection was extended to the posterior third midline. Final histopathology was consistent with cavernous hemangioma.

Conclusion: The modified Kole technique proved viable as the postoperative results were considered satisfactory. Tongue volume was uniformly reduced in length and width enabling mouth and jaw closure while tongue sensation and mobility were preserved. Feeding, speech intelligibility and cosmesis were markedly improved. Future application of this modification may prove its usefulness.

\section{Keywords: macroglossia; glossectomy; congenital macroglossia}

Macroglossia is an enlargement of the tongue that leads to functional and aesthetic problems. Although uncommon, this disorder has a variety of etiologies and cause significant morbidity. ${ }^{1}$ Macroglosia may be defined as either true macroglossia or relative macroglossia. In true macroglossia, the tongue size is larger than normal, whereas in relative macroglossia, the oral cavity is not large enough to accommodate the tongue. ${ }^{1,2}$

Vascular anomalies encompass vascular tumors and malformations, which involve the head and neck $70 \%$ to $80 \%$ of the time. Treatment depends on the site, size, and appearance of the lesion and the functional and aesthetic problems. In general, medical therapy is ineffective for congenital hemangiomas. ${ }^{3}$ Functional and aesthetic problems were the main indication for surgery in this case.

Glossectomy approaches include peripheral and midline resections providing either reduction in length and/or width. ${ }^{4}$ Among these, the Kole technique reduces the length and thickness of the anterior third of the tongue but does not address the base leaving it thick and wide. ${ }^{4}$ We present a modified Kole technique to solve this problem in a child with macroglossia. 


\section{CASE REPORT}

A 2-year-old boy presented to us with a congenitally enlarged tongue and associated difficulty feeding and phonating. On physical examination, the tongue was enlarged, increased in both length and width. In its resting state, protruded between the upper and lower teeth, with drying and fissuring at the tip. (Figure 1) Dribbling of saliva and a prognathic mandible were also present. No other physical abnormalities were noted. A CT scan of the oral cavity revealed a markedly enlarged tongue involving at least the anterior $2 / 3$ with outward protrusion.

\section{Surgical Technique}

The objectives of surgery were to enable mouth and jaw closure while maintaining tongue mobility and sensation. The tongue was maintained in place using silk sutures at the tip and on each side of the tongue. An outline of the glossoplasty incision and neurovascular bundle were made. (Figure 2) Using an Evac' 70 XTRA HP Coblation"' wand (ArthroCare Corp., Austin, TX, USA), a wedge-shaped partial glossectomy of the anterior $1 / 3$ of the tongue was performed followed by an extended midline triangular incision with the apex pointing posteriorly over the middle $1 / 3$. Tongue margins were approximated using Polyglactin 910 sutures (Vicryl 3.0, Ethicon, Johnson \& Johnson, NJ, USA). (Figure 3)

\section{Surgical Outcomes}

Tongue volume was uniformly reduced in both length and width. Blood loss was minimal and no dessication or charring of tissues was noted. His tongue healed uneventfully. The final histopathologic result was consistent with cavernous hemangioma.

One week postoperatively, the patient still had habitual mouth opening but could close his mouth and jaw on conscious effort. There was marked improvement in phonation intelligibility and feeding. (Figure 4)

On follow-up at 9 months, there was no limitation in tongue movement. He did not have any feeding problems. His habit of keeping his mouth open had already disappeared. No general and taste sensation problems were noted. Speech was intelligible, however he had difficulty producing the " $r$ " speech sound and there was still prognathism of the mandible. (Figure 5)

\section{DISCUSSION}

The decision to surgically treat macroglossia should be based in part on assessment of the level of functional debility and cosmetic problems. Indications for surgery include airway obstruction, speech difficulties, feeding problems and cosmesis. The basis for surgical success include proper position of the tongue in the oral cavity, functional tongue mobility, mouth opening and closure, improvement in feeding, articulation, preservation of sensation and taste, and airway improvement. ${ }^{2,46}$ In this case, indications for surgery included speech difficulties, feeding problems and cosmesis.

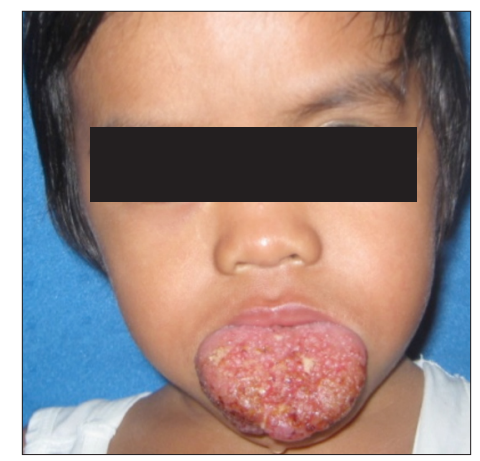

Figure 1. (front view) Tongue in resting position
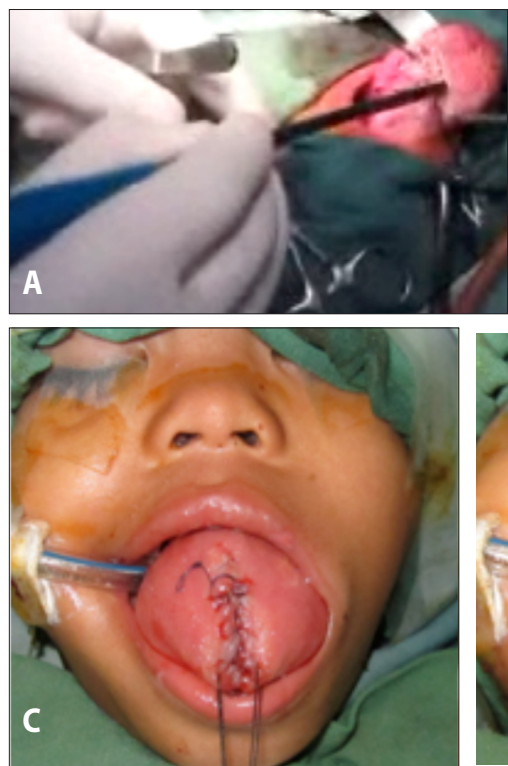

Figure 3. Wedge-shaped partial glossectomy of anterior third A. followed by extended midline triangular incision $\mathbf{B}$. and reapproximation $\mathbf{C}, \mathbf{D}$.

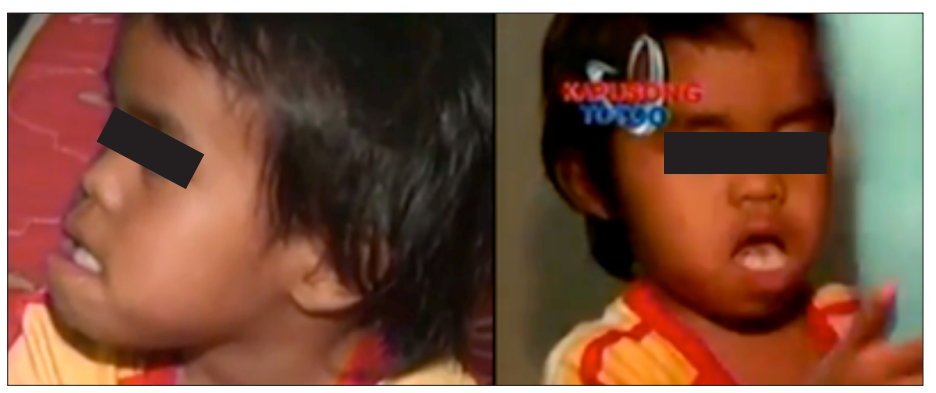

Figure 4. One week post operatively, still with habitual mouth opening but able to close mouth on conscious effort.

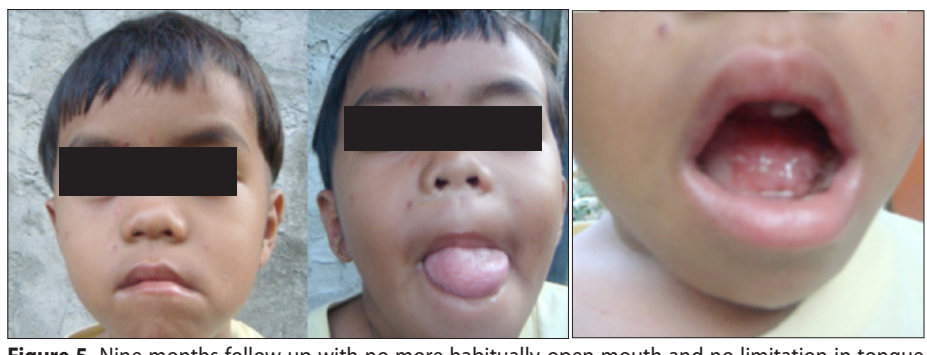

Figure 5. Nine months follow up with no more habitually-open mouth and no limitation in tongue movement. 


\section{SURGICAL INNOVATIONS AND INSTRUMENTATION}

A number of different approaches for tongue reduction have been advocated. Rather than using one approach for all patients, each case should be evaluated and the appropriate surgical approach chosen. ${ }^{6}$ The techniques are subdivided into median line and peripheral glossectomies. ${ }^{2}$ Regardless of the approach taken, the initial resection should be conservative to prevent permanent problems from overly aggressive resection. ${ }^{6}$

In 1950, Edgerton described a technique consisting of an elliptical excision along the center of the tongue with a view to spare the nerves,

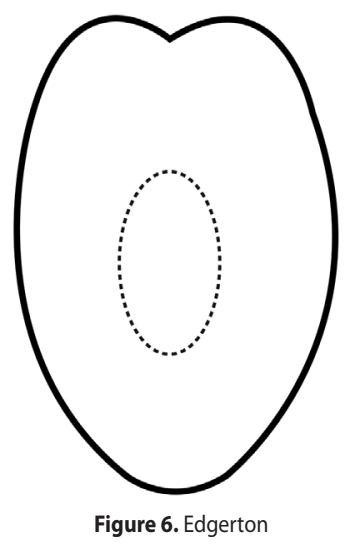

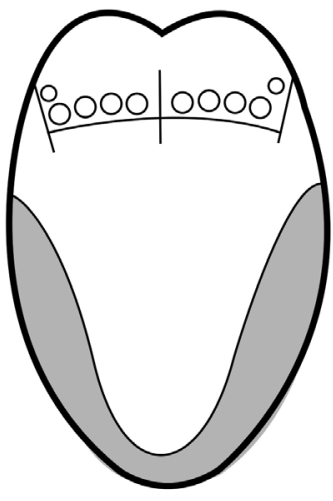

Figure 7. Dingman and Grabb

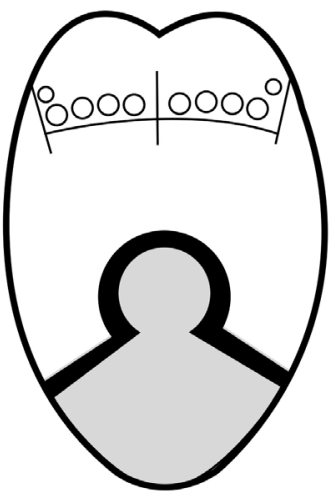

Figure 9. Morgan

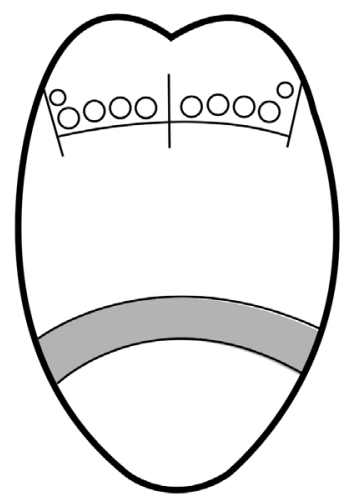

Figure 8. Gupta

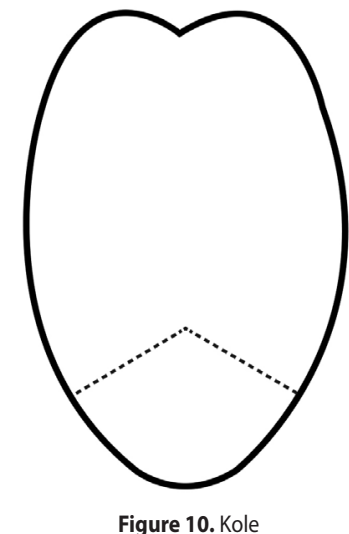

artery and papillae.,55 (Figure 6) The technique only reduces the width and does not reduce thickness and length., ${ }^{2,4}$ Peripheral excision techniques described by Dingman and Grabb, and Gupta suffer from the drawback of reducing the bulk of the tongue at the periphery while leaving the center and base bulky. ${ }^{4,5}$ (Figures 7 and 8) To combat the problem of an ankylosed globular tongue seen in some anterior tongue reductions, Morgan et al. described the keyhole subtotal glossectomy, wherein a posterior circular incision was added to the anterior wedge excision. (Figure 9) Keyhole glossectomy decreases both length and thickness of the anterior tongue. ${ }^{2,4,5}$

In 1965, Kole proposed an anterior triangular wedge excision of the tongue. (Figure 10) This technique reduced the length and thickness of the anterior third of the tongue but did not address the base of the tongue, leaving it thick and wide. ${ }^{4,5}$ In our case, the initial anterior wedge excision following the Kole technique provided adequate reduction in tongue length but width reduction was unsatisfactory. Hence, we modified the technique by extending the apex of the anterior triangular wedge to the posterior third midline providing additional and adequate reduction in tongue width. We preserved the neurovascular bundle that lies approximately midway between the lateral tongue margin and the tongue midline. Further tongue width reduction via the posterior midline triangular wedge was achieved while sparing the proximal portion of the neurovascular bundle, as the excision did not encroach into the area of the bundle, thus sparing tongue mobility and sensation.

Our modification of the Kole technique proved to be viable as the postoperative results were considered satisfactory. There was minimal blood loss. Tongue volume was uniformly reduced in both length and width enabling mouth and jaw closure while tongue sensation and mobility were preserved. Appearance, feeding, and speech intelligibility were markedly improved although difficulty in uttering " $r$ " speech sound was noted. This could be attributed to the patient's age, as the " $r$ " speech sound is only accurately used by $75 \%$ of children by age 5 years. ${ }^{7}$ Future application of this modification may demonstrate its usefulness.

\footnotetext{
REFERENCES

1. Murthy P, Laing MR. Macroglossia. BMJ. 1994 Nov;309(6966):1386-7. DOI: http://dx.doi. org/10.1136/bmj.309.6966.1386 PubMed PMID: 7819836 PMCID: PMC2541322.

2. Cymrot M, Teixeira F, Sales F, Neto F. Subtotal glossectomy by modified keyhole lingual resection technique for the treatment of true macroglossia. Rev Bras Cir Plást. 2012 Jan-Mar; 27(1):165-9. DOI: http://dx.doi.org/10.1590/S1983-51752012000100028.

3. Perkins JA, Chen EY. Vascular anomalies of the head and neck. In: Flint PW, Haughey BH, Niparko JK, Richardson MA, Robbins KT, Thomas JR, editors. Cummings otolaryngology head and neck surgery, $5^{\text {th }}$ ed. vol 3. Philadelphia: Mosby Elsevier; 2010. p. 2822-25.

4. Davalbhakta A, Lamberty BG. Technique for uniform reduction of macroglossia. Br J Plast Surg. 2000 Jun; 53(4): 294-97. DOI: 10.1054/bjps.1999.3311 PubMed PMID: 10876252.

5. Myers EN. Tongue reduction procedures. Operative otolaryngology: Head and neck surgery, $2^{\text {nd }}$ ed. vol 1. Philadelphia: Saunders / Elsevier; 2008. p.161-67.

6. Taher A. Surgical correction of the enlarged tongue. The Internet Journal of Head and Neck Surgery. 2008;3(1). [Cited 2013 Nov]. Available from: http://ispub.com/IJHNS/3/1/5989\#.

7. Gard A, Gilman L, Goman, J. Speech and Language Development Chart, 2nd Ed. Austin TX:ProEd 1993. [cited 2014 Oct]. Available from: http://www.ccr4kids.org/Portals/0/pdfs/Language\%20 Development\%20Chart.pdf.
} 